\title{
Noise Reduction Provided by Trees in an Urban University Campus ${ }^{\star}$
}

\author{
İnanç Taş $^{1 * *}$ iD, Halit Büyüksakalı ${ }^{2}$ \\ ${ }^{1}$ Bursa Technical University, Faculty of Forestry, 16310 Bursa, Turkey \\ ${ }^{2}$ Muğla Sitkı Koçman University, Köyceğiz Vocational School, Muğla, Turkey
}

\begin{abstract}
In urban universities, there are various noise sources such as roads, railways, construction activities that disturb staffs and students and cause undesirable environment for higher education. In this study, noise reduction effects of trees were investigated in the urban campus of Bursa Technical University (BTU) located in Yildırm province of Bursa, Turkey. The campus was surrounded by a major inter-city road with a heavy traffic at the north and there is a large hospital at the south. There is a tree fence along the north boarder and there are groups of trees particularly at the north. In field study, the peak noise level data were collected for 5 minutes in two periods (Morning: 09:00-11:00 and Afternoon: 14:00-16:00) from total of 64 points which were homogenously distributed in the campus. Additional noise data were also collected from outside and inside of tree fence along the north border and from midpoint of each tree group. The coordinates of the noise data points were recorded by a GPS and a noise level layer was generated in ArcGIS 10.4.1. Then, noise map of campus was generated using kriging function based on spatial interpolation of noise data. The results indicated that the average peak noise level was $65.6 \mathrm{dBA}$ in the morning period and $66.1 \mathrm{dBA}$ in the afternon period. The maximum peak noise level of $103.6 \mathrm{dBA}$ was reached in the morning period, while maximum peak noise level was $101.6 \mathrm{dBA}$ in the afternoon period. The average peak noise level within the tree groups were $53.7 \mathrm{dBA}$ (maximum $59.3 \mathrm{dBA}$ ) and $54.1 \mathrm{dBA}$ (maximum $61.3 \mathrm{dbA}$ ) in two periods, respectively. It was also found that tree fences reduced the noise level by $24.9 \mathrm{dBA}$ and $26.3 \mathrm{dBA}$ in two periods, respectively. The results revealed that trees within urban campus are important to reduce noise effect.
\end{abstract}

Keywords: Noise analysis, natural noise barriers, noise map, BTU Campus

\section{Introduction}

With the rapid population growth, heavy traffic, urbanization, the development of technological tools and machinery, practical solutions have been produced in many areas and significant benefits have been provided for humanity. Although these developments that make life easier are beneficial for people, they threaten the environment and human health by causing various damages. Especially when we look at environmental pollution, serious pollutants such as wastewater, polluting gases, dust substances, chemicals and hospital wastes harm both the environment and people. In addition to these, noise, which is a serious pollutant, affects people physically and psychologically.

In general, noise can be described as unpleasant, unwanted and intolerable sounds (Watts, 1995). Especially in urban areas with heavy traffic, the quality of life decreases considerably due to noise effects. The high traffic network and vehicle density in places close to natural areas such as educational areas, hospitals, resting places and parks cause serious levels of noise.
Being in noisy places for a long time causes significant hearing loss. It also causes problems such as sleep disorders, stress, and decreased ability to do work (Güler and Çobanoğlu, 1994). Especially in people exposed to noise levels of $65 \mathrm{dBA}$ and above, irregular sleep, behavioral disorders, physiological disorders and many other disorders occur (Zannin et al., 2002). Some information on the effects of noise on human is given in Table 1.

Although noise pollution is increasing day by day, different studies are carried out to determine noise levels and to find noise-preventing solutions. Sound levels are measured in many different areas, such as offices, urban environments, education and health institutions, and measures are to be taken. In a related study conducted in the city center of Sivas in Turkey, the highest monthly noise level was measured as $84.7 \mathrm{dBA}$ in September, and the lowest noise level as 69.3 in April and October (Özyonar and Peker, 2008). Although these values are dangerous for human health, they also exceed the noise levels in the regulations.

\footnotetext{
${ }^{*}$ This study was partially presented in INES 2019

** Corresponding Author: Tel: +90 2243003430 E-mail: inanc.tas@btu.edu.tr 
Table 1. Effects of different noise levels on human health

\begin{tabular}{|c|c|c|}
\hline Level & Intensity (Decibels) & Impact on Human Health \\
\hline 1. Degree & $30 \mathrm{~dB}(\mathrm{~A})-65 \mathrm{~dB}(\mathrm{~B})$ & Discomfort, anger, sleep disorder and concentration disorder \\
\hline 2. Degree & $65-90 \mathrm{~dB}(\mathrm{~B})$ & $\begin{array}{l}\text { Physiological reactions, increase in blood pressure, } \\
\text { acceleration of heartbeat and respiration, decrease in pressure } \\
\text { in the cerebral fluid, sudden reflexes }\end{array}$ \\
\hline 3. Degree & $90-120 \mathrm{~dB}(\mathrm{~B})$ & Increased physiological reactions, headaches \\
\hline 4. Degree & $120 \mathrm{~dB}(\mathrm{~B})$ & Persistent damage to the inner ear, impaired balance \\
\hline 5. Degree & $140 \mathrm{~dB}(\mathrm{~B})$ & Serious brain damage \\
\hline
\end{tabular}

In another study, noise measurements were made from the same points in 2007 and 2014 before and after the traffic routing project for the Square Park and Fatih Park in the city of Trabzon in Turkey, and the changes between these years were monitored. In the results, it was determined that there was a decrease of $14.25 \mathrm{dBA}$ in Square Park and $6.16 \mathrm{dBA}$ in Fatih Park between 2007 and 2014. On the other hand, it was observed that there were changes in noise levels from place to place due to the fact that the parks had playgrounds and cafés and they were also used as recreation areas (Bayramoğlu et al., 2014).

The university campuses located in the urban areas are subject to noise pollution due to mainly traffic related noises. University campuses consisted of various kinds of noise sensitive buildings which are used for educational and social purposes. In order to investigate the potential effects of noise on these noise sensitive buildings, noise maps are developed for the campus areas. Aydin (2015) conducted a study where noise map of ITU Maslak Campus in the city of İstanbul was developed for controlling noise pollution. They reported that very few of buildings in the campus were higher than the limit value of day time noise during the working hours. In another study, Gunes and Ozyavuz (2018) evaluated the traffic and human noise in Namık Kemal University Campus in the city of Tekirdağ in Tukey. They measured noise levels from 28 points in the campus area in the morning, noon, and evening hours and then a noise map was developed accordingly. They found that the noise ranges were $44 \mathrm{dBA}$ and $78 \mathrm{dBA}$, while the highest maximum noise level was measured as $78.5 \mathrm{dBA}$ at noon.

Previous studies showed that tree groups provide significant noise reduction effects. Noise penetrating through the trees is reduced due to refraction and transmission between trees (Aydin, 2015). The main factors that affect the noise reduction include visibility, width, height and length of the tree belts (Fang and Ling, 2003). Tree groups and tree belts can be effective noise barriers to be used in the university campuses located in the urban areas. In this study, the effectiveness of tree groups and tree fences in noise prevention was investigated based on noise measurements made in and around BTU Mimar Sinan Campus, which is located in the urban area of Bursa in Turkey.

\section{Material and Methods \\ 2.1. Study Area}

The study was carried out at Bursa Technical University Mimar Sinan Campus in Y1ldırım district of Bursa province (Figure 1). The coordinates of the study area are between $40^{\circ} 11^{\prime} 29^{\prime \prime}-40^{\circ} 11^{\prime} 10^{\prime \prime}$ North latitude and $29^{\circ} 7^{\prime} 38^{\prime \prime}-29^{\circ} 7^{\prime} 55^{\prime \prime}$ East longitude. Although there are roads on all four sides of the campus, three of them are in the form of main roads and there is heavy traffic. On the other hand, a hospital located in the south of the campus is effective in noise generation in the region. During the measurements, the air temperature was 18-22 ${ }^{\circ} \mathrm{C}$ and the humidity was between $60 \%-75 \%$.

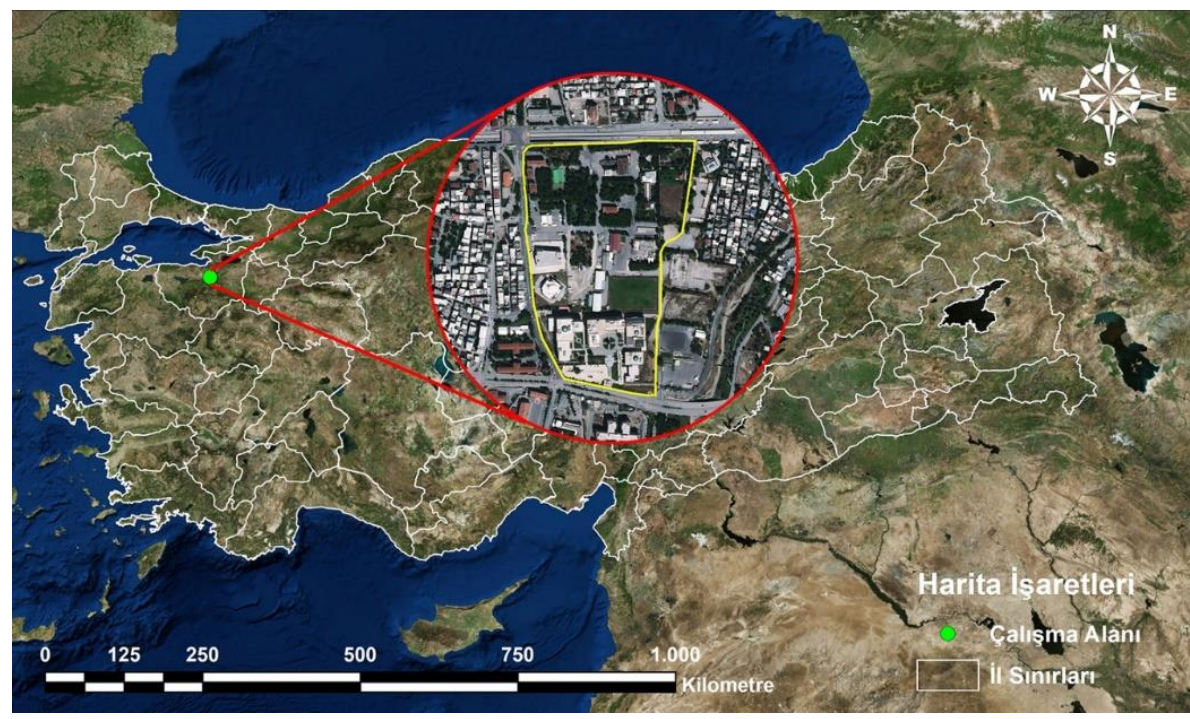

Figure 1. Mimar Sinan Campus of Bursa Technical University in the city of Bursa 


\subsection{Noise Data Collection}

Data on the highest noise levels in and around the campus were measured between 09:00 - 10:00 in the morning and 14:00 - 16:00 in the afternoon in March 2019. Noise levels were determined for a period of 5 minutes at a total of 64 points that were homogeneously distributed over the area. In the measurements made inside and outside the campus, the coordinates of each measurement point were recorded with the help of a handheld GPS. The device used in the measurements was the Extech EN300 model multi-measuring device (Figure 2). Some technical information about the device is given in Table 2.

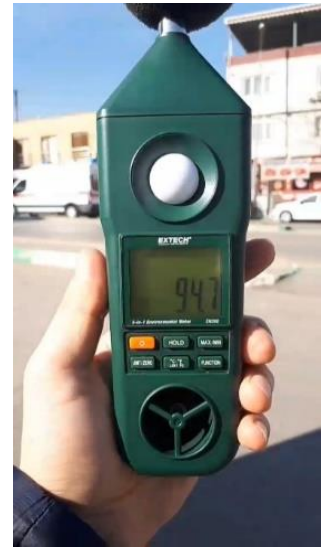

Figure 2. Extech EN300 multifunctional measuring device

\subsection{Office Works}

The total of 256 data collected in the noise measurements were transferred to a computer in the office environment and inputted into the ArcGIS 10.4.1 program where spatial analysis was carried out. The points recorded by the GPS were formed into shapefiles (point layer) with the ArcMAP module, and the noise data of these points for both morning and afternoon periods were entered by generating fields in the attribute table (Figure 3). Then, separate noise maps for morning and afternoon periods were produced with the Kriging tool under Raster Interpolation feature of 3D Analyst Tools under ArcToolBox. In generating the noise maps, "Ordinary" was chosen as the method in the Kriging window and "Linear" was chosen as the Semivariogram model. In the $\mathrm{Z}$ value field, the columns containing the noise data were selected separately for morning and afternoon measurements, and then maps were produced. Digital data layer of tree groups in the campus were generated based on the satellite image of the campus area.

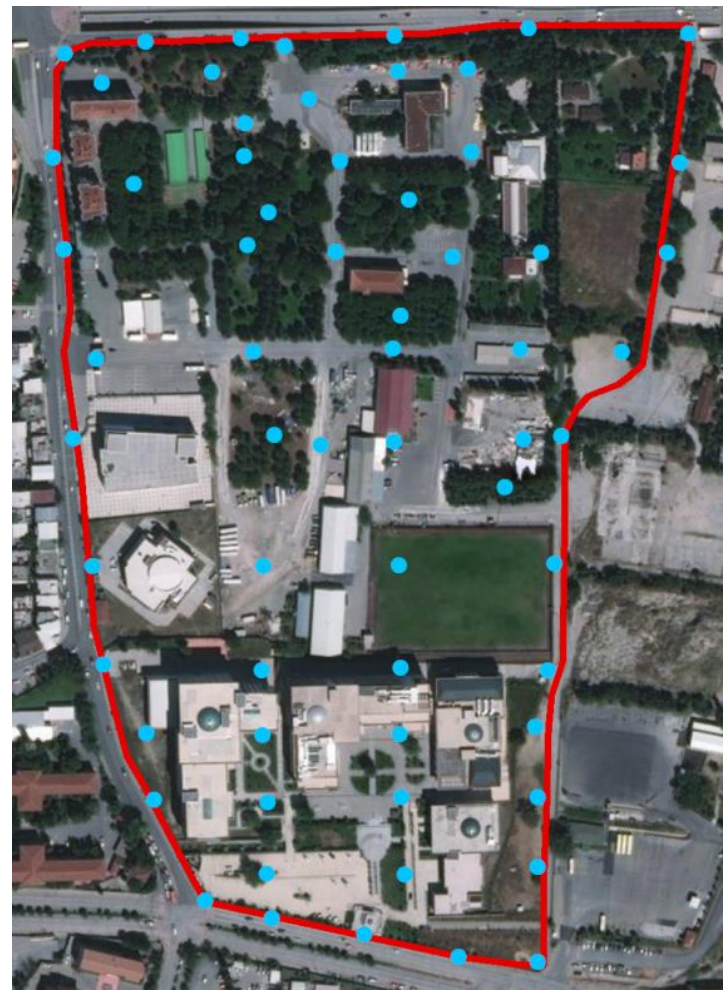

Figure 3. Noise data of the points taken by GPS in BTU campus

Table 2. Extech EN300 specifications (URL 1)

\begin{tabular}{lll}
\hline Specifications & Range & Basic Accuracy \\
\hline Air Speed & 0.4 to $30 \mathrm{~m} / \mathrm{s}$ & $\pm 3 \%$ \\
Light Level & 0 to $1860(0.1 \mathrm{Fc})$ & 0 to $20,000(1 \mathrm{Lux})$ \\
Temperature & 32 to $122^{\circ} \mathrm{F} / 0$ to $50^{\circ} \mathrm{C}\left(0.1^{\circ}\right)$ & $\pm 2.5^{\circ} \mathrm{F}, \pm 1.2^{\circ} \mathrm{C}$ \\
Relative Humidity & 10 to $95 \%(0.1 \%)$ & $\pm 4 \% \mathrm{RH}$ \\
Noise & 35 to $130 \mathrm{~dB}(0.1 \mathrm{~dB})$ & $\pm 1.4 \mathrm{dBA}$ \\
Power & $6 \times$ AAA batteries $(1.5 \mathrm{~V})$ & \\
Dimensions & $248 \times 70 \times 34 \mathrm{~mm}$; Vane: $31 \mathrm{~mm}$ & \\
Weight & $335 \mathrm{~g}$ \\
\hline
\end{tabular}

\section{Results and Discussion}

The results indicated that the average noise levels in the morning and afternoon periods were $65.6 \mathrm{dBA}$ and $66.1 \mathrm{dBA}$, respectively. These noise levels exceeded the noise limit values set for education areas according to the noise regulation applied for highways (Table 3). In the morning period, maximum noise measurement was recorded as $101.6 \mathrm{dBA}$, while it was up to $103.6 \mathrm{dBA}$ in the morning period. Ozer et al. (2014) conducted a similar study where the noise levels were measured on the Ataturk University campus in Erzurum, in Turkey. They reported that the average noise level was 62.70 $\mathrm{dBA}$ exceeding the average permitted value of $55 \mathrm{dBA}$. 
Table 3. Road environmental noise limit values (URL 2)

\begin{tabular}{|c|c|c|c|c|c|c|}
\hline & \multicolumn{3}{|c|}{ Planned/Renovated/Repaired roads } & \multicolumn{3}{|c|}{ Existing roads } \\
\hline & Morning & Evening & Night & Morning & Evening & Night \\
\hline & $(\mathrm{dBA})$ & $(\mathrm{dBA})$ & $(\mathrm{dBA})$ & $(\mathrm{dBA})$ & $(\mathrm{dBA})$ & $(\mathrm{dBA})$ \\
\hline $\begin{array}{l}\text { Areas where education, } \\
\text { culture and health areas as } \\
\text { well as summer and camping } \\
\text { areas are dominant among } \\
\text { noise-sensitive uses. }\end{array}$ & 60 & 55 & 50 & 65 & 60 & 55 \\
\hline $\begin{array}{l}\text { From the areas where } \\
\text { commercial buildings and } \\
\text { noise-sensitive uses exist } \\
\text { together, areas where } \\
\text { residences are densely } \\
\text { located }\end{array}$ & 63 & 58 & 53 & 68 & 63 & 58 \\
\hline $\begin{array}{l}\text { From the areas where } \\
\text { commercial buildings and } \\
\text { noise sensitive uses exist } \\
\text { together, areas where } \\
\text { workplaces are concentrated }\end{array}$ & 65 & 60 & 55 & 70 & 65 & 60 \\
\hline Industrial areas & 67 & 62 & 57 & 72 & 67 & 62 \\
\hline
\end{tabular}

In the measurements considering the noise reduction of the tree groups, the average noise levels were measured as $53.7 \mathrm{dBA}$ (maximum: $59.3 \mathrm{dBA}$ ) and 54.1 dBA (maximum: 61.3 dBA) for the morning and afternoon periods, respectively. Besides, it was found that tree fences reduced the sound level by $24.9 \mathrm{dBA}$ and $26.3 \mathrm{dBA}$ in both time periods, respectively. Pal et al. (2000) reported that $50 \mathrm{~m}$ wide tree belt can reduce the sound level by $10 \mathrm{dBA}$. This results showed that availability of tree groups and tree fences within the urban campus areas play important role in terms of reducing the noise level under the limit value of day time noise during the working hours.
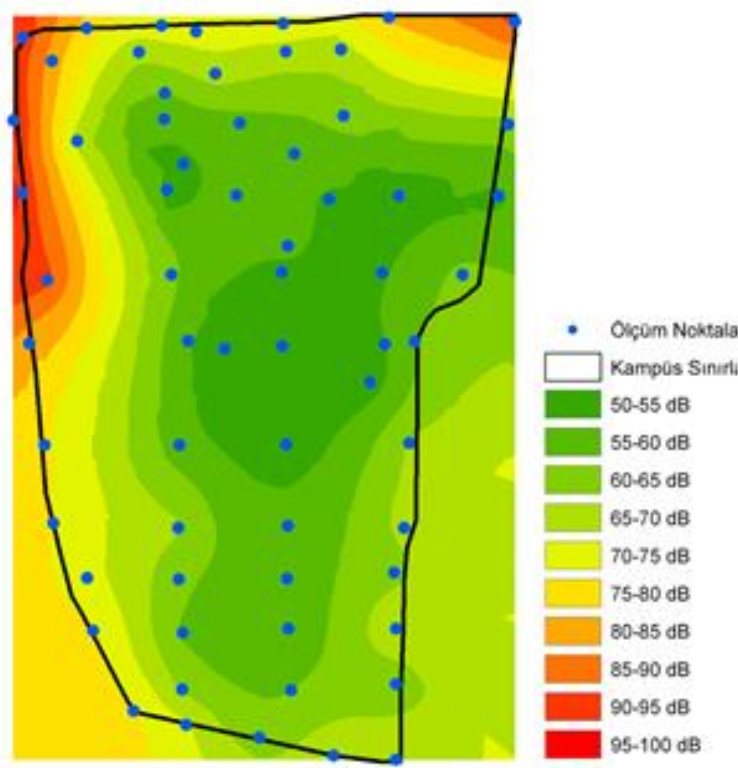

Figure 5. The noise maps developed for morning (left) and afternoon (right) periods
Noise maps of the campus were developed from the morning and afternoon measurements with the kriging function based on spatial interpolation of the noise data (Figure 5). Thanks to the colorings in the generated noise maps, regions where the noise is intense and less intense can be easily distinguished. Noise maps, defined as a numerical model of noise sources, can be effectively used in the assessment and control of the noise impact (Probst and Huber, 2003). On the other hand, two maps of time periods (i.e. morning and afternoon) were developed from the measurements in these areas to indicate the noise effects of tree groups, which can serve as natural barrier (Figure 6). It has been observed that there is a visible reduction in noise levels in the maps.

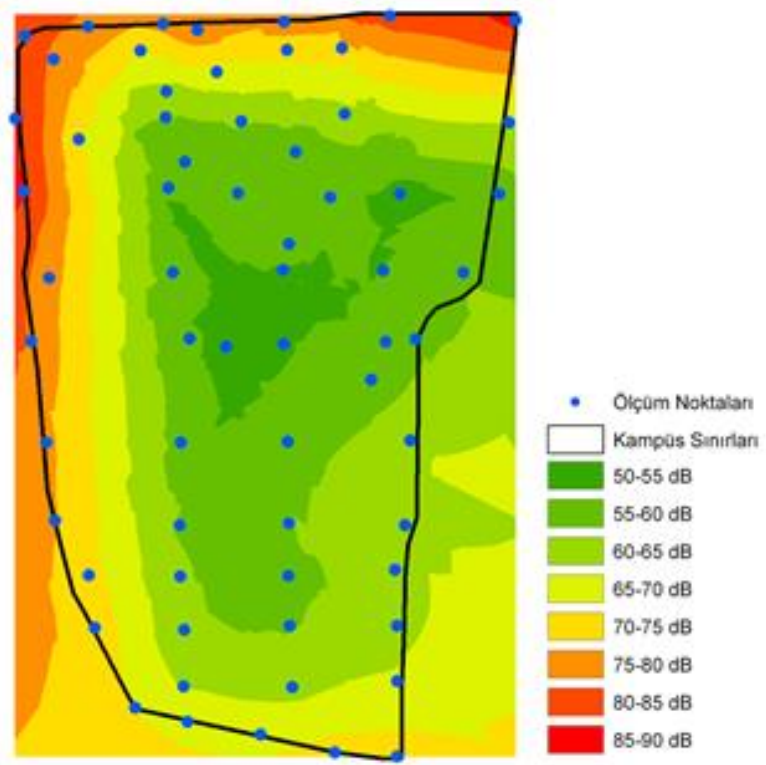



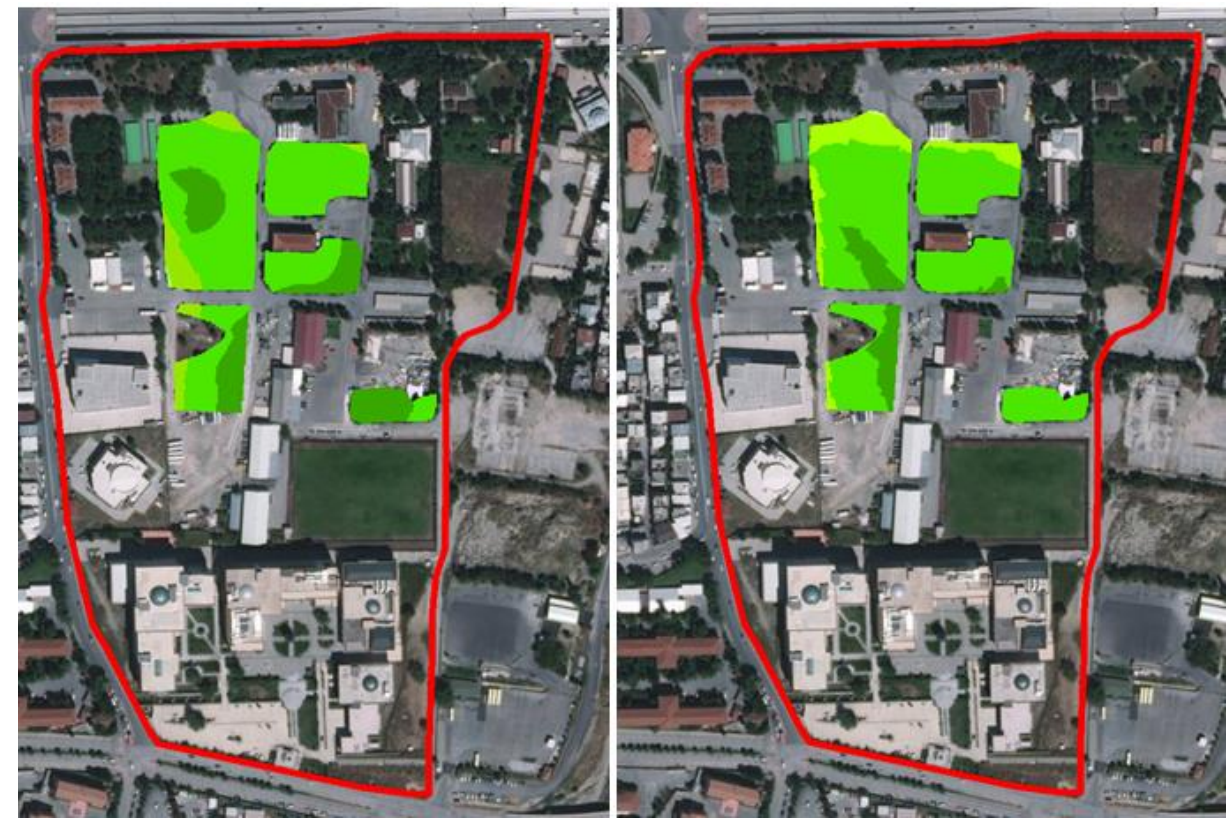

Figure 6. The noise maps of the tree groups developed for morning (left) and afternoon (right) periods

During the measurements around the campus, there was an increase in sound levels during ambulance passes due to the presence of a hospital nearby. However, lower intensity sounds were measured in areas where traffic lights were located. The reason for this is that the vehicle engines produce lower noise when idling and the traffic pauses for a short time.

The results indicated that trees reduced the sound intensity and kept the noise level under threshold level specified for the education areas. It is anticipated that the tree fences to be established where necessary around the campus can reduce noise-related disruptions in education and training activities. Especially in places such as education areas, parks and hospitals, around roads with heavy traffic, tree belts can be beneficial with sound insulation as well as visual effect (Fang and Ling, 2003).

\section{Conclusions}

The noise map of the urban campus of BTU was generated based on noise data measurements and the tree groups were evaluated in terms of their noise reduction effects. The results indicated that trees reduce the sound intensity within the campus area. It was observed that the sound values in these areas do not exceed the sound threshold level in education areas and it is estimated that the tree fences to be established around the campus will have a positive effect on preventing noise. In this way, it is thought that noise-related disruptions in education and training activities will be reduced. Noise maps to be produced using these and similar methods will be very useful in planning for noise sensitive areas. In addition, noise insulation can be provided by installing tree fences or tree groups in appropriate places. Especially in places such as education areas, parks and hospitals around roads with heavy traffic, tree plantation will be beneficial with sound insulation as well as visual effect.
Ethics Committee Approval: N/A.

Peer-review: Externally peer-reviewed.

Author Contributions: Concept: İ.T.; Design: İ.T. and H.B.; Supervision: İ.T.; Resources: İ.T. and H.B.; Data Collection: İ.T.; Analysis: İ.T. and H.B.; Literature Search: İ.T. and H.B.; Writing Manuscript: İ.T. and H.B.; Critical Review: İ.T. and H.B.

Conflict of Interest: The authors have no conflicts of interest to declare.

Financial Disclosure: The authors declared that this study has received no financial support

Cite this paper as: Taş, İ., Büyüksakalı, H., 2021. Noise Reduction Provided by Trees in an Urban University Campus, European Journal of Forest Engineering, 7(1):26-31.

\section{References}

Aydın, B., 2015. Noise Mapping on a University Campuse Area: Case Study for Istanbul Technical University Ayazaga Campus. MSc Thesis. İstanbul Technical University, İstanbul, Turkey. $98 \mathrm{p}$.

Bayramoğlu, E., Özdemir, E., Demirel, Ö., 2014. The Effect of Noise Pollution on City Parks and Proposed Solutions: Case of Urban Trabzon, Inönü University Journal of Art and Design, 4(9):35-42.

Fang, C., Ling, D., 2003. Investigation of the noise reduction provided by tree belts, Landscape and Urban Planning, 63(2003):187-195.

Gunes, M., Ozyavuz, M., 2018. Noise Mapping of Namık Kemal University Campus (Tekirdag-Turkey) by Using Geographic Information Systems, Journal of Environmental Protection and Ecology, 19(1):186195. 
Güler, Ç., Çobanoğlu, Z. 1994. Noise. Basic Resource Probst, W., Huber, B. 2003. The Sound Power Level of Series of Environmental Health, Turkish Ministry of Health. No: 19.42 p. Cities, Sound and Vibration, 263:14-17.

Ozer, S., Zengin, M., Yilmaz, H. 2014. Determination of

URL 1 http://www.extech.com/display/?id=14468 (Last access: 15 May 2021)

the Noise Pollution on University (Education) URL Campuses: a Case study of Ataturk University, Ecology, 23(90):49-54.

http://www.resmigazete.gov.tr/eskiler/2008/03/2008 0307-6.htm (Last access: 15 May 2021)

Özyonar, F., Peker, İ. 2008. Investigation of The Watts, G.R. 1995. A comparison of noise measures for Environmental Noise Pollution in Sivas City Centre. Ecology, 18(69):75-80.

Pal, A.K., Kumar, V., Saxena, N.C. 2000. Noise Zannin, P.H.T., Diniz, F.B., Barbosa, W.A. 2002. attenuation by Green Belts, Journal of Sound and Vibration, 234 (1):149-165 assessing vehicle noisiness. Journal of sound and vibration, 180(3):493-512.

Environmental noise pollution in the city of Curitiba, Brazil. Applied Acoustics, 63(4):351-358. 